\title{
The effect of dapagliflozin on alanine aminotransferase as a marker of liver inflammation: updated results from the $A B C D$ dapagliflozin audit
}

\author{
THOMAS SJ CRABTREE, ${ }^{1,2}$ MAHENDER YADAGIRI, ${ }^{3}$ IAN GALLEN, ${ }^{4}$ SUZANNE PHILLIPS, ${ }^{5}$ ALISON EVANS, \\ ANURITA ROHILLA, ${ }^{6}$ DEVESH SENNIK, ${ }^{7}$ ALEX BICKERTON, ${ }^{8}$ SUSANNAH ROWLES, ${ }^{9}$ ISKANDAR IDRIS, ${ }^{10}$ \\ ROBERT EJ RYDER, ${ }^{3}$ ON BEHALF OF THE ABCD DAPAGLIFLOZIN AUDIT CONTRIBUTORS
}

\begin{abstract}
Introduction: People with type 2 diabetes are known to be at increased risk of non-alcoholic fatty liver disease (NAFLD). There is increasing evidence of diabetes treatments with benefits of also improving NAFLD. Although mostly focused on glucagon-like peptide 1 agonists, sodium-glucose linked transporter 2 inhibitors may also have some promise in improving markers of NAFLD.

Method: Data were extracted from the $A B C D$ nationwide dapagliflozin audit tool. Alanine aminotransferase (ALT) was available in these data and was used as a marker of liver inflammation. Patients were stratified based on baseline ALT levels to see if this predicted response to treatment.

Results: 1,873 patients were included for analysis (mean \pm SD age $58.7 \pm 10$ years, $60.8 \%$ male, median duration of diabetes 3.5 years (IQR 1.5-9)) and were followed up in this study for an average of 11.4 months. Where known $(n=280), 60.8 \%$ of these were Caucasian. Baseline $\mathrm{HbA}_{1 \mathrm{c}}$ was $78 \pm 17.2$ $\mathrm{mmol} / \mathrm{mol}$, weight $102.1 \pm 22.5 \mathrm{~kg}$ and body mass index (BMI) $34.2 \pm 7.6 \mathrm{~kg} / \mathrm{m}^{2}$. Median ALT reduction overall was $4 \mathrm{U} / \mathrm{L}$ (95\% Cl 3 to 4; $p<0.001)$. Reductions in weight (3.2 kg; $95 \%$ $\mathrm{Cl} 2.9$ to 3.5$)$, BMI $\left(0.9 \mathrm{~kg} / \mathrm{m}^{2}, 95 \% \mathrm{Cl} 0.6\right.$ to 1.2$)$ and $\mathrm{HbA}_{1 \mathrm{c}}$

University Hospitals of Derby and Burton NHS Trust; University of Nottingham; Sandwell and West Birmingham Hospitals NHS Trust, UK City Hospital, Birmingham, UK

Sandwell and West Birmingham Hospitals NHS Trust, UK

${ }^{4}$ Royal Berkshire NHS Foundation Trust, UK

Cheltenham General Hospital, Cheltenham, UK

${ }^{6}$ Chief Pharmacist, West Essex CCG, Essex, UK

Consultant \& Clinical Lead Diabetes \& Endocrinology, Princess Alexandra Hospital, Harlow, UK

Yeovil District Hospital NHS Trust, Somerset, UK

9 Pennine Acute Hospitals NHS Trust, Manchester, UK

10University Hospitals of Derby and Burton NHS Trust; University of Nottingham, UK
\end{abstract}

Address for correspondence: Dr Thomas SJ Crabtree Department of Diabetes, Royal Derby Hospital, Uttoxeter Road, Derby, DE22 3NE

E-mail: t.crabtree@nhs.net

https://doi.org/10.15277/bjd.2020.239
(10.8 $\mathrm{mmol} / \mathrm{mol}, 95 \% \mathrm{Cl} 10.1$ to 11.5$)(0.9 \%, 95 \% \mathrm{Cl} 0.8 \%$ to $1.0 \%)$ were all significant $(p<0.001)$. Where ALT was elevated at baseline (>19 U/L female; $>30 \mathrm{U} / \mathrm{L}$ male), the median reduction in ALT was $5 \mathrm{U} / \mathrm{L}$ in women $(95 \% \mathrm{Cl} 4$ to $6 ; \mathrm{p}<0.0001)$ and $10 \mathrm{U} / \mathrm{L}$ in men (95\% Cl 8 to $11 ; p<0.0001)$. Stratified into three groups by ALT using the male reference range and twice this, there were reductions in ALT in all groups, which was greatest (24 U/L $95 \% \mathrm{Cl} 20$ to 27 ) in the subgroup with baseline ALT > $59 \mathrm{U} / \mathrm{L}$.

Conclusion: Our observational data suggest significant reductions in ALT as a possible marker of liver inflammation in those taking dapagliflozin. This appears to be greatest in those with the most elevated levels at baseline.

Br J Diabetes 2020;20:19-24

Key words: dapagliflozin, real-world, alanine aminotransferase (ALT), non-alcoholic fatty liver disease, SGLT-2

\section{Introduction}

Non-alcoholic fatty liver disease (NAFLD) is a growing concern in people with diabetes. Both conditions seem to share a common pathophysiological process although causative links have not been fully established. ${ }^{1,2}$ The prevalence is estimated to be $30-70 \%$ depending on the source, ${ }^{3,4}$ and the clinical phenotype of NAFLD in people with diabetes appears to be more aggressive than in those without; higher rates of both progression to cirrhosis and hepatocellular carcinoma have been noted. ${ }^{5}$ The presence of NAFLD also compounds the cardiovascular risk of a person with diabetes, being a risk factor on its own independent of glycaemic control, lipid profiles and blood pressure. ${ }^{1}$

Diabetes management that targets this co-morbidity is therefore likely to improve patient outcomes overall. Evidence exists for the benefits of both pioglitazone and glucagon-like peptide 1 receptor agonists (GLP-1) in improving markers of liver inflammation and damage, ${ }^{6}$ most notably alanine aminotransferase (ALT) and, although fairly specific (estimates around $85 \%$ ), is not particularly sensitive (around 45\%)., Nevertheless, ALT is the surrogate biomarker of choice for inferring improvement in the fatty infiltration and inflammation of NAFLD used across multiple 
studies, and there is evidence to suggest it correlates well with more invasive tests, perhaps most importantly with the presence of fatty infiltration and fibrosis on biopsies. ${ }^{7}$

Dapagliflozin is a sodium-glucose link transporter 2 (SGLT-2) inhibitor and there is much evidence to support its use with favourable outcomes in terms of $\mathrm{HbA}_{1 \mathrm{c}}$, weight, cardiovascular and renal outcomes, both alone and in combination therapy with other oral hypoglycaemic agents or insulin in randomised controlled trials and real-world data analyses. ${ }^{8-15}$ Evidence for its effect on NAFLD is more limited, especially compared with GLP-1 agonists such as liraglutide which are supported by large clinical trials specifically looking at NAFLD outcomes. ${ }^{16}$ Trial data from Korea suggest that SGLT-2 in combination with metformin is superior to dipeptidyl peptidase-4 inhibitors in improving ALT, and the significance of this improvement was maintained when adjusting for weight loss. ${ }^{17}$ There are further randomised controlled data showing improvements in liver fibrosis based on transient elastography as well as improvements in ALT and gamma-glutamyltranspeptidase with dapagliflozin compared with placebo, although the numbers were fairly small. ${ }^{18}$ Realworld data are also available, showing a significant reduction in ALT in 3,667 Canadian patients independent of weight loss and other variables and with greater reductions in ALT observed in those with higher baseline levels. ${ }^{19}$

The dapagliflozin audit was initially launched in 2012 and collection ceased in 2018, although anonymised data from clinical commissioning groups (CCGs) continue to be integrated when they become available. The aim of this analysis of the $A B C D$ dapagliflozin audit data is to establish whether the following hypotheses hold true for our real-world cohort of patients: (1) dapagliflozin use is associated with a reduction in ALT levels; (2) baseline elevated ALT levels predict response in terms of ALT reduction, $\mathrm{HbA}_{1 \mathrm{c}}$ reduction and weight reduction; and (3) ALT reduction associated with dapagliflozin use is correlated with the amount of weight lost.

Patients who discontinued dapagliflozin at any point during the audit were also analysed to assess the reasons for discontinuing and to describe their baseline characteristics as part of a sensitivity analysis.

\section{Methods}

Data were obtained from the integration of $A B C D$ UK and international audit data as well as data from CCGs. Patients were excluded if they did not have a minimum dataset of baseline ALT and follow-up (defined as 6-18 months after commencing) or if they discontinued dapagliflozin prior to having a repeat ALT measurement. Data for $\mathrm{HbA}_{1 \mathrm{c}}$ and weight at baseline and follow-up (if available) were also extracted.

The population was then stratified into groups using the following two methods and each method of stratification was analysed separately:
1. Female and male, normal and raised ALT groups based on gender-specific reference ranges (female, ALT $\leq 19 \mathrm{U} / \mathrm{L}$; male, ALT $<30 \mathrm{U} / \mathrm{L}){ }^{20}$

2. Normal (as defined by male reference range ALT $<30 \mathrm{U} / \mathrm{L}$ ), mildly elevated (ALT 30-59 U/L) and markedly elevated based on twice the upper limit of the normal male reference range (ALT >59U/L).

The selection and stratification of patients is outlined in Figure 1.

Skewed data were analysed using Wilcoxon signed-rank tests (paired tests) and Friedman tests (difference between groups). For non-skewed data, paired t-tests were used for paired data whilst linear regression and Spearman's correlation coefficients were calculated to express the relationship between the different variables (ALT, weight, $\mathrm{HbA}_{1 \mathrm{c}}$ ) and baseline ALT as well as between change in weight and change in ALT.

Any patients who discontinued dapagliflozin during the time frame of the audit to date were reviewed separately to describe their baseline characteristics and identify common reasons why the medication was discontinued as part of a sensitivity analysis.

\section{Results}

The baseline characteristics of the 1,873 patients included for analysis are shown Table 1 . The population had a mean \pm SD age of $58.7 \pm 10$ years and $60.8 \%$ were male. Ethnicity data were available for only 208 of those included and $60.8 \%$ of these were British or Irish. The mean $\pm \mathrm{SD}$ baseline $\mathrm{HbA}_{1 c}$ was $9.2 \pm 1.57 \%$ or $78 \pm 17.2 \mathrm{mmol} / \mathrm{mol}$. The mean \pm SD weight at baseline was $102.1 \pm 22.5 \mathrm{~kg}$ with a body mass index (BMI) of $34.2 \pm 7.6 \mathrm{~kg} / \mathrm{m}^{2}$. The average duration of diabetes at baseline was 3.5 years (IQR 1.5-9).

Figure 1. Flowchart showing the inclusion and stratification into groups of patients from the $A B C D$ dapagliflzoin audit programme

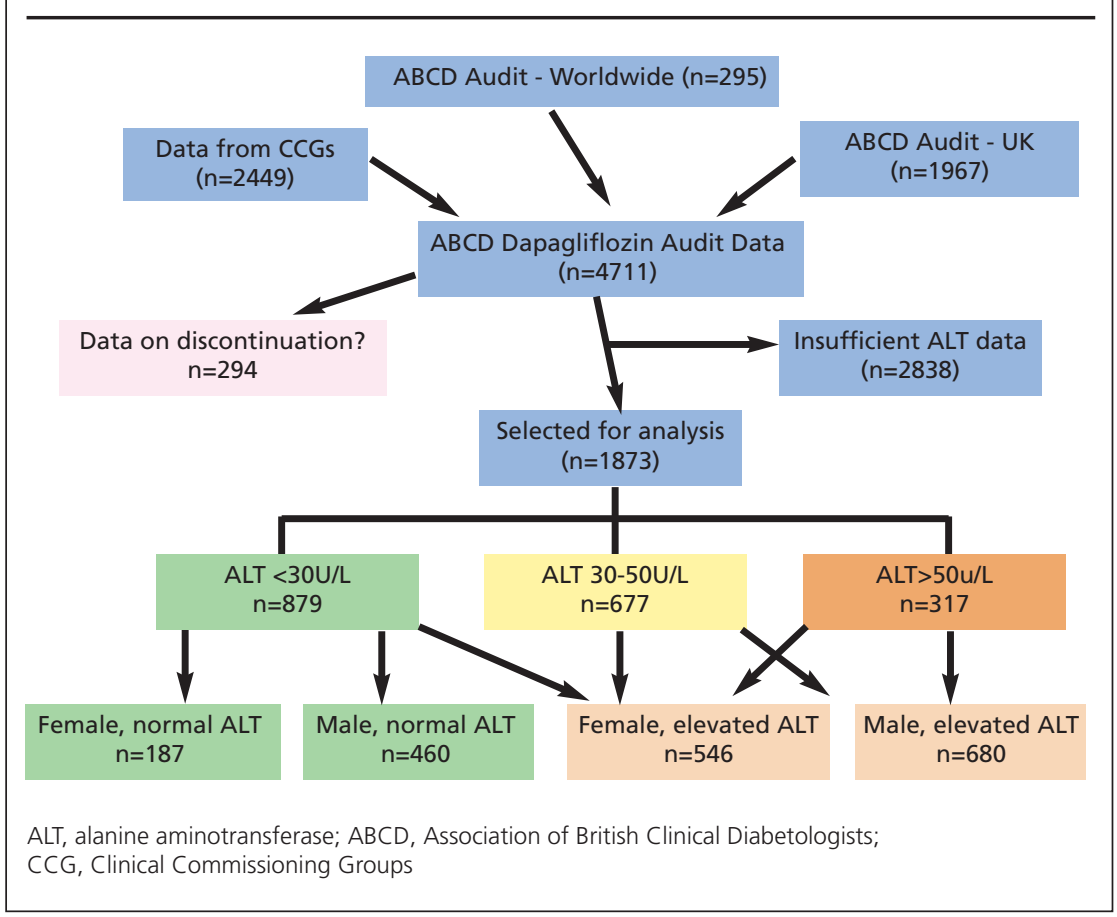


The baseline characteristics of the male and female subgroups are shown in Table 2. This demonstrates similarities across the groups and, although the men with raised baseline ALT (>30 U/L) were heavier at baseline, the $\mathrm{BMI}$ of this group is comparable to that of the other groups.

Those who discontinued dapagliflozin were broadly similar in baseline characteristics to the above, other than having a longer duration of diabetes at baseline (median 12 years) and a greater proportion of those discontinuing were female (51.3\%). The main reasons for discontinuing were efficacy $(28 \%)$, followed by urinary tract infections (11\%) and genital infections (usually candidiasis) (20\%).

Over a mean follow-up of 11.4 months the median ALT reduction across the entire population was $4 \mathrm{U} / \mathrm{L}$ (95\% $\mathrm{Cl} 3$ to 4; $\mathrm{p}<0.001)$. Reductions in weight $(3.2 \mathrm{~kg} ; 95 \%$ $\mathrm{Cl} 2.9$ to 3.5), BMI (0.9 $\mathrm{kg} / \mathrm{m}^{2} ; 95 \% \mathrm{Cl} 0.6$ to 1.2$)$ and $\mathrm{HbA}_{1 \mathrm{c}}(10.8 \mathrm{mmol} / \mathrm{mol}$; 95\% Cl 10.1 to 11.5$)$ (0.9\%; $95 \% \mathrm{Cl} 0.8 \%$ to $1.0 \%$ ) were all significant $(p<0.001)$.

In the subgroups with elevated ALT at baseline ( $>19$ $\mathrm{U} / \mathrm{L}$ female; >30 U/L male) there was a median reduction in ALT of $5 \mathrm{U} / \mathrm{L}$ in women $(95 \% \mathrm{Cl} 4$ to 6 ; $\mathrm{p}<0.0001)$ and of $10 \mathrm{U} / \mathrm{L}$ in men $(95 \% \mathrm{Cl} 8$ to $11 \mathrm{U} / \mathrm{L}$; $\mathrm{p}<0.0001)$. In women with normal baseline ALT there was a statistically significant increase in ALT of $1 \mathrm{U} / \mathrm{L}$ (95\% $\mathrm{Cl}-2$ to $0 ; \mathrm{p}<0.0001)$ and in men there was a median decrease of $1 \mathrm{U} / \mathrm{L}(95 \% \mathrm{Cl} 1$ to 2; $\mathrm{p}<0.0001)$; the clinical significance of such small
Table 1 Baseline characteristics of observed population

\begin{tabular}{|c|c|c|}
\hline Characteristic & & $n=1,873$ \\
\hline Mean \pm SD age, years, & & $58.7 \pm 10.0$ \\
\hline Male, \% & & 60.8 \\
\hline Median (IQR) diabetes duration, years & & $3.5(1.5-9)$ \\
\hline Caucasian, \% (where known, $\mathrm{n}=280$ ) & & 63.9 \\
\hline Mean $\mathrm{HbA}_{1 \mathrm{c}}$ & $\begin{array}{l}\% \pm \mathrm{SD} \\
\mathrm{mmol} / \mathrm{mol} \pm \mathrm{SD}\end{array}$ & $\begin{array}{l}9.2 \pm 1.57 \\
78.0 \pm 17.2\end{array}$ \\
\hline Mean \pm SD BMI, kg/m² & & $34.2 \pm 7.6$ \\
\hline Mean \pm SD weight, $\mathrm{kg}$ & & $102.1 \pm 22.5$ \\
\hline Median (IQR) ALT, U/L & $\begin{array}{l}\text { Male } \\
\text { Female }\end{array}$ & $\begin{array}{l}31(22-44) \\
33(24-49) \\
27(19-39)\end{array}$ \\
\hline Median (IQR) ALT at baseline, U/L & $\begin{array}{l}\text { Female: normal ALT } \\
\text { Female: raised ALT } \\
\text { Male: normal ALT } \\
\text { Male: raised ALT }\end{array}$ & $\begin{array}{l}15(13-17) \\
33(26-46) \\
22(19-25) \\
43(36-58)\end{array}$ \\
\hline
\end{tabular}

ALT, alanine aminotransferase; BMI, body mass index; IQR, interquartile range; SD, standard deviation.

Table 2 Baseline characteristics of subgroups stratified by normal and raised ALT (using gender specific cut-offs: female $<19 \mathrm{U} / \mathrm{L}$, male $<30 \mathrm{U} / \mathrm{L}$ ) from this population

\section{Characteristic}

Number 187

Mean \pm SD age, years

Median (IQR) diabetes duration, years

Caucasian, \% (where known, $n$ given)

Mean $\mathrm{HbA}_{10}$

$\% \pm \mathrm{SD}$ $\mathrm{mmol} / \mathrm{mol} \pm \mathrm{SD}$

Mean \pm SD BMI, $\mathrm{kg} / \mathrm{m}^{2}$

Mean \pm SD weight, $\mathrm{kg}$
Female

Normal ALT

546

$56.9 \pm 10.4$

$3.7(1.7-10.3)$

$41.2 \%(n=51)$

$9.2 \pm 1.8$

$77.3 \pm 20.2$

$35.4 \pm 10.5$

$92.7 \pm 20.4$
Raised ALT

460

$57.3 \pm 10.2$

$3.5(1.6-8)$

$62.1 \%(n=95)$

$9.2 \pm 1.5$

$77.0 \pm 16.6$

$34.6 \pm 8.0$

$95.0 \pm 20.0$
Male

Normal ALT

Raised ALT

680

$61.5 \pm 9.8 \quad 58.4 \pm 9.4$

$3.9(1.6-10.4) \quad 3.4(1.4-7.8)$

$68.9 \%(n=87) \quad 75 \%(n=100)$

$9.2 \pm 1.85$

$77.3 \pm 20.2$

$35.4 \pm 10.5$

$9.5 \pm 1.55$

$79.7 \pm 16.4$

$34.1 \pm 6.2$

$109.5 \pm 20.8$
$\mathrm{ALT}$, alanine aminotransferase; $\mathrm{BMI}$, body mass index; IQR, interquartile range; SD, standard deviation.

Figure 2. Bar chart showing median alanine aminotransferase (ALT) in each group at baseline and follow-up for normal (female $\leq 19 \mathrm{U} / \mathrm{L}$; male $<30 \mathrm{U} / \mathrm{L}$ ) and raised ALT at baseline in patients commencing dapagliflozin. Error bars represent interquartile ranges. All results significant to $\mathrm{p}<0.0001$

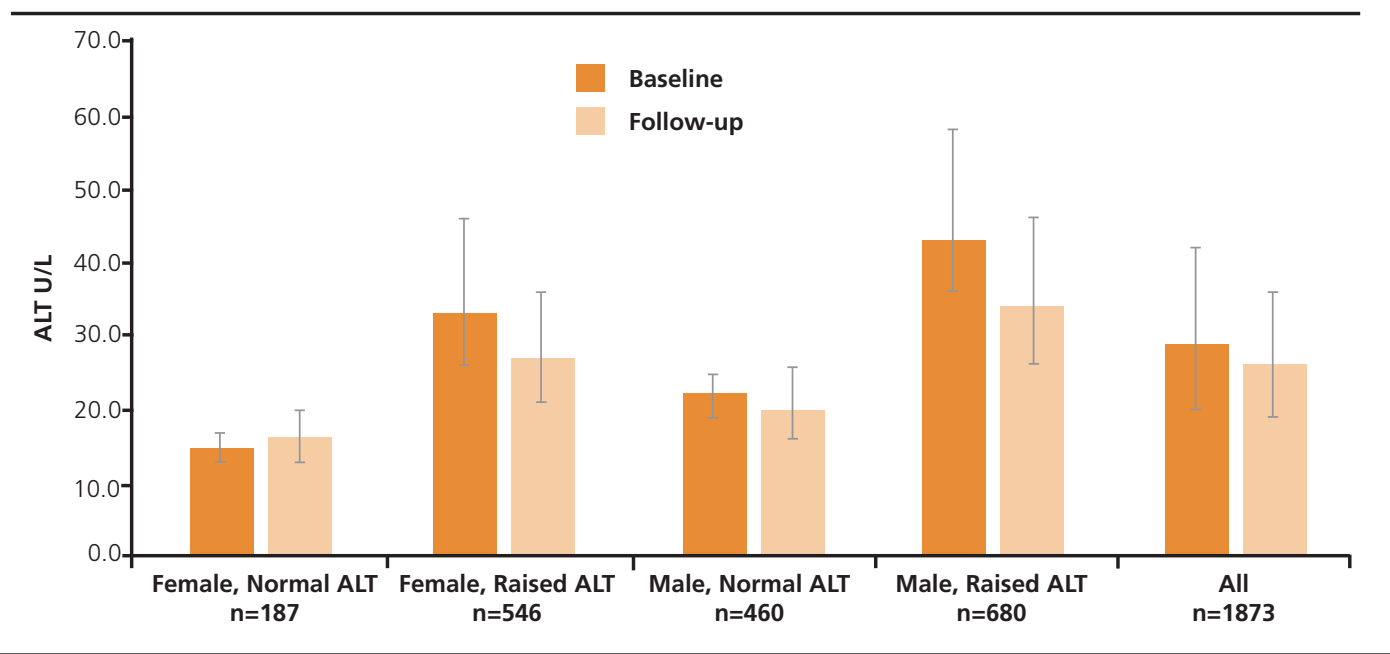


Figure 3. Bar chart demonstrating the median change in alanine aminotransferase (ALT) from baseline grouped as per baseline ALT readings as follows: female, normal $\operatorname{ALT}(n=187)$; female, raised $\operatorname{ALT}(n=546)$; male, normal $\operatorname{ALT}(n=460)$ and male, raised $\operatorname{ALT}(n=680)$. Normal range female $\leq 19 \mathrm{U} / \mathrm{l}$; male $<30 \mathrm{U} / \mathrm{L}$. Error bars represent $95 \%$ confidence intervals. All results significant to $\mathrm{p}<0.0001$

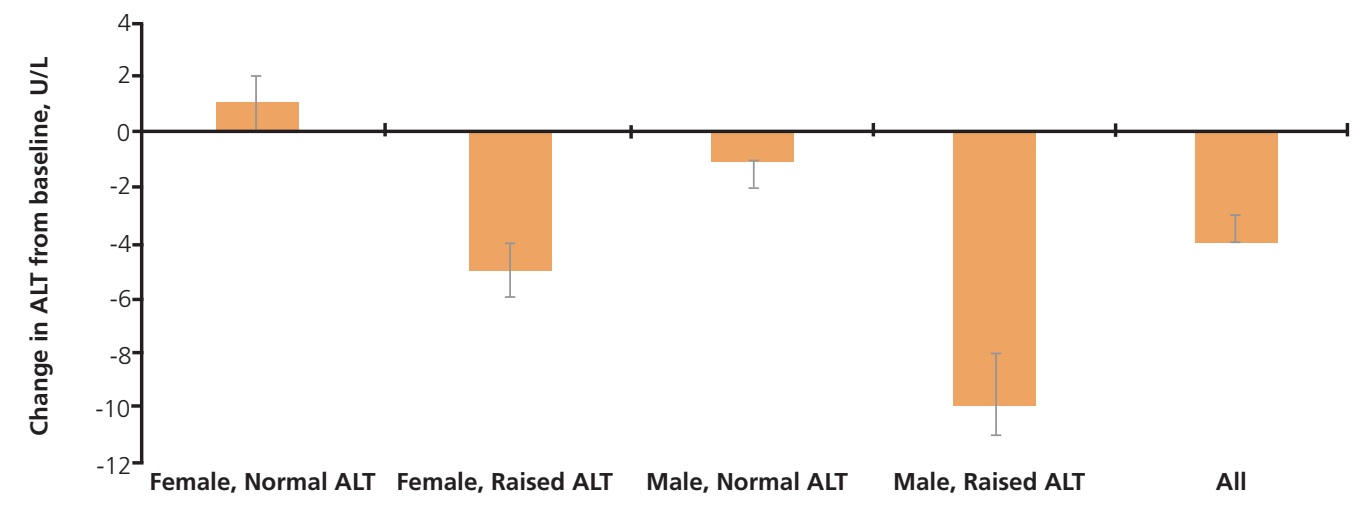

Figure 4. Bar chart showing median alanine aminotransferase (ALT) in each group at baseline when stratified into three groups defined by the male reference range $(<30 \mathrm{U} / \mathrm{L})$ and twice the upper limit of normal. Error bars represent interquartile ranges. All results significant to $\mathrm{p}<0.0001$

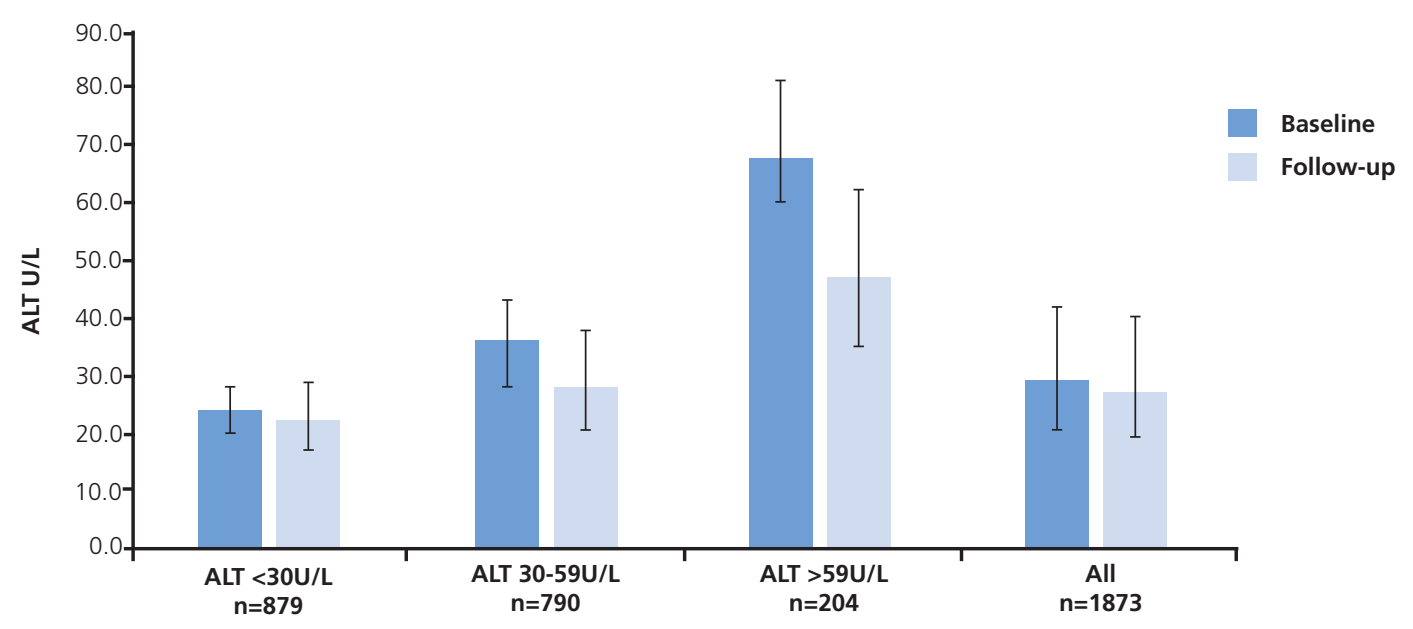

changes is unlikely to be of any relevance. The medians of each group with interquartile ranges are shown in Figure 2 and the changes in ALT with confidence intervals are shown in Figure 3.

When stratified into three groups based on baseline ALT as defined by the male reference range and twice the upper limit of normal, there were statistically significant $(p<0.0001)$ reductions in ALT in all three groups with the greatest reduction (24 $\mathrm{U} / \mathrm{L} ; 95 \% \mathrm{Cl} 20$ to 27 ) in the subgroup with markedly elevated baseline ALT (>59 U/L). The results are shown in Figure 4.

There were statistically significant differences between all groups in each analysis with the Friedman test (non-parametric analysis of variance) $p<0.0001$.

There was no correlation between baseline ALT and change in weight, but baseline ALT did significantly, though weakly, correlate positively with change in $\mathrm{HbA}_{1 \mathrm{c}}$ and more strongly with change in ALT. There was no correlation between change in weight and change in ALT $(p=0.16)$. Spearman's coefficients and $\mathrm{p}$ values are shown in Table 3.

Table 3 Spearman's rank correlation between baseline alanine aminotransferase (ALT) and metabolic and clinical outcomes in patients receiving dapagliflozin

\begin{tabular}{lll}
\hline Metabolic/clinical parameter & Spearman's rho & P value \\
Change in weight $(n=1,847)$ & $\leq 0.001$ & 0.8 \\
Change in $\mathrm{HbA}_{1 c}(n=1,861)$ & 0.004 & 0.003 \\
Change in ALT $(n=1,873)$ & 0.27 & $<0.0001$ \\
Change in weight vs change in ALT & $<0.001$ & 0.16
\end{tabular}




\section{Discussion}

\section{Main findings}

The subjects included in this analysis of the UK ABCD dapagliflozin audit had a median duration of diabetes of less than 5 years with raised BMls and out-of-target $\mathrm{HbA}_{1 \mathrm{c}}$ levels at baseline. Where the data are available, it suggests our dataset is generally representative of the UK population with $63.9 \%$ Caucasian ethnicity, albeit with a slightly stronger preponderance towards being male (60.8\%).

Those discontinuing dapagliflozin were more likely to be female and, in view of urinary and genital infections being common reasons for the discontinuation, it is likely that the predisposition of women towards these infections is the likely explanation for this disparity.

During the observed time period, dapagliflozin use was associated with significant reductions across the population in all parameters assessed in this audit: $\mathrm{HbA}_{1}$, weight, $\mathrm{BMI}$ and ALT. Although the reduction in ALT appears to be fairly small across the entire population, the reductions in ALT in individual subgroups (ie, those with raised ALT levels at baseline) is large and may be of clinical significance. Perhaps most striking is the reduction of $24 \mathrm{U} / \mathrm{L}(95 \% \mathrm{Cl} 20$ to $27 ; p<0.0001)$ observed in those with ALT levels at baseline more than twice the upper limit of normal. Additionally, Spearman's correlation reveals a positive correlation between baseline ALT and reduction in ALT. This suggests that those with the most elevated ALT levels at baseline are likely to see the greatest reduction in ALT and, by extension, potentially liver inflammation and NAFLD.

Baseline ALT did slightly predict the response of $\mathrm{HbA}_{1 \mathrm{c}}$ to dapagliflozin therapy but did not predict weight loss in our cohort. There was no correlation between change in weight and change in ALT $(\rho<0.001, p=0.16)$, suggesting that the effect of dapagliflozin may, in part, be independent of its effect in promoting weight loss.

\section{Strengths and limitations}

Using real-world data in an observational study such as this means the findings are likely to be generalisable to UK diabetes practice where off-licence use of medications may be encountered and users may have extremes of weight, $\mathrm{HbA}_{1 \mathrm{c}}$ or other factors compared with the strict inclusion criteria often used in randomised controlled trials. All data, test results and measurements included will have been taken as part of routine diabetes care. For this reason, it was not possible to provide a suitable control group. Additionally, we were only able to access specific information and were lacking other information on potential confounding factors such as other concomitant medications or alcohol use - either of which could have some impact on ALT readings.

ALT has certainly been found to be reflective of histological scores and imaging findings in previous studies, although concerns are noted on its use in NAFLD. ${ }^{4}$ It is difficult to incorporate such tests which are invasive or not part of routine care in observational data collection. Further studies are needed using multimodality assessments of liver fibrosis and NAFLD (eg, mag- netic resonance imaging, biopsy, transient elastography) to confirm that dapagliflozin is exerting a positive effect on liver outcomes beyond the scope of observational data.

\section{Interpretation}

There are not many studies for comparison assessing the impact of dapagliflozin on ALT. The randomised controlled trial which included multiple methods of assessment carried out by Shimizu et $a /^{18}$ showed more marked reductions in ALT from a similar baseline as well as improvement in other parameters including transient elastography score (which was the primary outcome measure). This study, however, had patients with markedly different BMls compared with our observational dataset - 73.9 $\mathrm{kg}$ at baseline compared with $102.1 \mathrm{~kg}$ in our study..

The Canadian observational data presented by Bajaj et a/19 provide perhaps the closest equivalent to our dataset, with similarities across all baseline characteristics including age, ALT and $\mathrm{BMI}$ although with a long duration of diabetes at commencement. They reported a similar decrease in ALT of $3.5 \pm 14.3 \mathrm{U} / \mathrm{L}$ across their entire population from baseline with statistical significance $(p<0.01)$. Additionally, they found very little change in their normal baseline ALT subgroups, with large changes observed in those with elevated ALT at baseline. This remained the case even when adjusting for weight and improvement in $\mathrm{HbA}_{1 \mathrm{c}}$, which made minimal if any change to the outcome (fitting with our data entirely).

Furthermore, both dapagliflozin and canagliflozin were found to be superior to liraglutide in achieving reduction in ALT, although only canagliflozin achieved a statistically significant difference. Our similar observational dataset from the UK ABCD liraglutide audit showed smaller reductions in ALT compared with those seen with dapagliflozin in this study.

\section{Implications for future research, policy and practice}

Although, including this study, there are two large observational studies suggesting an association between dapagliflozin use and reduction in ALT, trial data are somewhat limited, especially when compared with the large-scale randomised controlled trials that have been conducted to support the use of some other therapies, such as liraglutide. ${ }^{16}$

Most trials conducted on dapagliflozin include liver function tests as a measure of safety and not of efficacy in possibly treating NAFLD and, ultimately, more data are needed to confirm that dapagliflozin, and other SGLT-2 inhibitors, offer this additional benefit. If proven to do so, it may be that they are considered superior to liraglutide due to additional benefits accompanied by an easier mode of administration (ie, oral versus subcutaneous injection).

Additionally, it is not clear whether SGLT-2 inhibitors such as dapagliflozin have a weight loss-independent mechanism of action on NAFLD. Some animal-based experimental evidence suggests that SGLT-2 inhibitors may have a direct effect on alpha-cells in the pancreas, with subsequent glucagon secretion being a possible mediator of any direct effect on the liver. ${ }^{21,22}$ Ultimately, more evidence in human subjects is needed in this regard. 


\section{Key messages}

- In this analysis of our ABCD audit data, dapagliflozin was associated with statistically significant reductions in alanine aminotransferase (ALT)

- Those with higher levels of ALT at baseline had the greatest fall in ALT with treatment

- This may be suggestive of a role for dapagliflozin in improving non-alcoholic fatty liver disease in people with type 2 diabetes, but more data are needed

\section{Conclusions}

This observational study demonstrates the potential benefits of dapagliflozin in reducing ALT levels. These are real-world data so they are likely to be more generalisable than randomised controlled trial data. Due to a lack of large-scale trial evidence using multimodal assessments of liver function and markers of NAFLD, it is not clear whether this reduction in ALT represents true improvements in underlying liver pathology. Ultimately, more evidence is needed to confirm this relationship and affirm the potential role of dapagliflozin in the management of people with diabetes and co-morbid NAFLD.

Conflict of interest $T C, M Y, I G, S P, A E, A R, A B, S R$, II have nothing to disclose. REJR has received speaker fees, and/or consultancy fees and/or educational sponsorships from AstraZeneca, BioQuest, GI Dynamics, Janssen and Novo Nordisk. DS has received speaker fees/honoraria from Novo Nordisk, Sanofi, Boehringer Ingelheim, AstraZeneca and Merck.

Funding The $A B C D$ Nationwide Dapagliflozin audit is supported by an unrestricted grant by AstraZeneca.

Acknowledgement: The authors would like to thank the audit contributors (see Appendix 1 at www.bjd-abcd.com)

\section{References}

1. Targher G, Bertolini L, Padovani R, et al. Prevalence of nonalcoholic fatty liver disease and its association with cardiovascular disease among type 2 diabetic patients. Diabetes Care 2007;30(5):1212-18. https://doi.org/ 10.2337/dc06-2247

2. Targher G, Marchesini G, Byrne CD. Risk of type 2 diabetes in patients with non-alcoholic fatty liver disease: causal association or epiphenomenon? Diabetes Metab 2016;42(3):142-56. https://doi.org/10.1016/j.diabet. 2016.04.002

3. Hazlehurst JM, Woods C, Marjot T, Cobbold JF, Tomlinson JW. Non-alcoholic fatty liver disease and diabetes. Metabolism 2016;65(8):1096-108. https://doi.org/10.1016/j.metabol.2016.01.001

4. Rinella ME. Nonalcoholic fatty liver disease: a systematic review. JAMA 2015;313(22):2263-73. https://doi.org/10.1001/jama.2015.5370

5. Bril F, Cusi K. Management of nonalcoholic fatty liver disease in patients with type 2 diabetes: a call to action. Diabetes Care 2017;40(3):419-30. https://doi.org/10.2337/dc16-1787

6. Musso G, Cassader M, Rosina F, Gambino R. Impact of current treatments on liver disease, glucose metabolism and cardiovascular risk in non-alcoholic fatty liver disease (NAFLD): a systematic review and meta-analysis of randomised trials. Diabetologia 2012;55(4):885-904. https://doi.org/ 10.1007/s00125-011-2446-4

7. Suzuki A, Lymp J, St Sauver J, Angulo P, Lindor K. Values and limitations of serum aminotransferases in clinical trials of nonalcoholic steatohepatitis. Liver Int 2006;26(10):1209-16. https://doi.org/10.1111/j.1478-3231. 2006.01362.x

8. Ferrannini E, Ramos SJ, Salsali A, Tang W, List JF. Dapagliflozin monotherapy in type 2 diabetic patients with inadequate glycemic control by diet and exercise: a randomized, double-blind, placebo-controlled, phase 3 trial. Diabetes Care 2010;33(10):2217-24. https://doi.org/10.2337/dc10-0612

9. Furtado RHM, Bonaca MP, Raz I, et al. Dapagliflozin and cardiovascular outcomes in patients with type 2 diabetes mellitus and previous myocardial infarction. Circulation 2019;139(22):2516-27. https://doi.org/10.1161/CIRCULATIONAHA.119.039996

10. Jabbour SA, Hardy E, Sugg J, Parikh S, Study 10 Group. Dapagliflozin is effective as add-on therapy to sitagliptin with or without metformin: a 24-week, multicenter, randomized, double-blind, placebo-controlled study. Diabetes Care 2014;37(3):740-50. https://doi.org/10.2337/dc13-0467

11. Kato ET, Silverman MG, Mosenzon O, et al. Effect of dapagliflozin on heart failure and mortality in type 2 diabetes mellitus. Circulation 2019; 139(22):2528-36. https://doi.org/10.1161/CIRCULATIONAHA.119.040130

12. Mosenzon O, Wiviott SD, Cahn A, et al. Effects of dapagliflozin on development and progression of kidney disease in patients with type 2 diabetes: an analysis from the DECLARE-TIMI 58 randomised trial. Lancet Diabetes Endocrinol 2019;7(8):606-17. https://doi.org/10.1016/S22138587(19)30180-9

13. Wilding J, Bailey C, Rigney U, Blak B, Kok M, Emmas C. Dapagliflozin therapy for type 2 diabetes in primary care: changes in $\mathrm{HbA} 1 \mathrm{C}$, weight and blood pressure over 2 years follow-up. Prim Care Diabetes 2017; 11(5):437-44. https://doi.org/10.1016/j.pcd.2017.04.004

14. Wilding JP, Woo V, Soler NG, et al. Long-term efficacy of dapagliflozin in patients with type 2 diabetes mellitus receiving high doses of insulin: a randomized trial. Ann Intern Med 2012;156(6):405-15. https://doi.org/ 10.7326/0003-4819-156-6-201203200-00003

15. Wilding JPH, Rigney U, Blak B, Nolan ST, Fenici P, Medina J. Glycaemic, weight, and blood pressure changes associated with early versus later treatment intensification with dapagliflozin in United Kingdom primary care patients with type 2 diabetes mellitus. Diabetes Res Clin Pract 2019; 155:107791. https://doi.org/10.1016/j.diabres.2019.107791

16. Armstrong MJ, Houlihan DD, Rowe IA, et al. Safety and efficacy of liraglutide in patients with type 2 diabetes and elevated liver enzymes: individual patient data meta-analysis of the LEAD program. Aliment Pharmacol Ther 2013;37(2):234-42. https://doi.org/10.1111/apt.12149

17. Choi DH, Jung $\mathrm{CH}$, Mok JO, Kim CH, Kang SK, Kim BY. Effect of dapagliflozin on alanine aminotransferase improvement in type 2 diabetes mellitus with non-alcoholic fatty liver disease. Endocrinol Metab (Seoul) 2018;33(3):387-94. https://doi.org/10.3803/EnM.2018.33.3.387

18. Shimizu M, Suzuki K, Kato K, et al. Evaluation of the effects of dapagliflozin, a sodium-glucose co-transporter-2 inhibitor, on hepatic steatosis and fibrosis using transient elastography in patients with type 2 diabetes and nonalcoholic fatty liver disease. Diabetes Obes Metab 2019;21(2):285-92. https://doi.org/10.1111/dom.13520

19. Bajaj HS, Brown RE, Bhullar L, Sohi N, Kalra S, Aronson R. SGLT2 inhibitors and incretin agents: associations with alanine aminotransferase activity in type 2 diabetes. Diabetes Metab 2018;44(6):493-9. https://doi.org/ 10.1016/j.diabet.2018.08.001

20. Prati D, Taioli E, Zanella A, et al. Updated definitions of healthy ranges for serum alanine aminotransferase levels. Ann Intern Med 2002;137(1):110. https://doi.org/10.7326/0003-4819-137-1-200207020-00006

21. Suga T, Kikuchi O, Kobayashi M, et al. SGLT1 in pancreatic alpha cells regulates glucagon secretion in mice, possibly explaining the distinct effects of SGLT2 inhibitors on plasma glucagon levels. Mol Metab 2019;19:1-12. https://doi.org/10.1016/j.molmet.2018.10.009

22. Qiang S, Nakatsu Y, Seno $Y$, et al. Treatment with the SGLT2 inhibitor luseogliflozin improves nonalcoholic steatohepatitis in a rodent model with diabetes mellitus. Diabetol Metab Syndrome 2015;7:104. https://doi.org/ 10.1186/s13098-015-0102-8 


\section{Appendix 1. ABCD nationwide ad worldwide dapagliflozin audit contributors The following are those whom we know about}

$A B C D$ nationwide dapagliflozin audit - initial setup, maintenance and nationwide analysis:

Ryder REJ, Adamson K, Bailey CJ, Walton C, Thong KY, Sen Gupta P, Cull ML, Yadagiri M, Crabtree T. Statistician: Blann A

\section{England}

Aintree University Hospital NHS Foundation Trust (University Hospital Aintree): Steele T, Wilding J, Yunus A. Ashford And St Peter's Hospitals NHS Foundation Trust: Ince J. Barnsley Hospital NHS Foundation Trust (Barnsley District General Hospital): Jones H, Sloan G. Barts Health NHS Trust (St Bartholomew's Hospital): Glynn N, Leslie RDG. Barts Health NHS Trust (The Royal London Hospital): Chowdhury T, Coppack SW. Bridgnorth Medical Practice (Bridgnorth Medical Practice): Morris D. Bromley CCG (Selsdon Park Medical Practice): Cheah Y, Lovie K. Church View Health Centre, South Kirby (Little Lane): Diggle J. Countess of Chester Hospital NHS Trust (Countess of Chester Hospital): Nair S, Qaffaf M. County Durham And Darlington NHS Foundation Trust (Darlington Memorial Hospital): Kamaruddin S, Khan U, Partha P, Peter P, Tarigopula G, Tee SA. Doncaster And Bassetlaw Hospitals NHS Foundation Trust (Bassetlaw Hospital): Chaturvedi P, Payne G. City Hospitals Sunderland NHS Foundation Trust (Sunderland Royal Hospital): Joshi A, Lee A, Nayer R. Dorset County Hospital NHS Foundation Trust (Cerne Abbas Surgery): Murphy H. Dorset County Hospital NHS Foundation Trust (Dorset County Hospital): Graja A, Macklin A, Wotherspoon F. Dudley Group Hospitals NHS Foundation Trust (Russells Hall Hospital): Pang T. East and North Hertfordshire NHS Trust (Queen Elizabeth II Hospital): Phylactou M, Darzy K, Winocour P. East Kent Hospitals University NHS Foundation Trust (Ashford Hospital): Chuah L, Richards J. East Kent Hospitals University NHS Foundation Trust (William Harvey Hospital): Chuah LL, Poddar A. East London NHS Foundation Trust (East Ham Memorial Hospital): Laverty J, Totaram V. East Sussex Healthcare NHS Trust (Conquest Hospital): Ahmad S, Batson D, Castro E, Combes A, Dashora U, Govindan R, Kumar S, Moor C, Ravelo M. Frimley Park Hospital NHS Foundation Trust (Frimley Park Hospital): Bingham E, Kurera I, Zaman M. Great Western Hospitals NHS Foundation Trust (The Great Western Hospital): Bhattacharya B, Broughton C, Ghaffar I, Vaks V. Guy's And St Thomas' NHS Foundation Trust (Guy's And St Thomas' NHS Foundation Trust): Joshi M, McGowan B. Hampshire Hospitals NHS Foundation Trust (Royal Hampshire County Hospital): Chong JLV. Hull and East Yorkshire Hospitals NHS Trust (Hull Royal Infirmary): Deshmukh H, Sathyapalan T, Varghese J, Walton C. King's College Hospital NHS Foundation Trust (Orpington Hospital): Allinson R, Allitt C, Amo-Konado S, Barratt M, Cheah YS, Cunningham S, Fisher N, Hopkins D, Hussey S, Lewis D, Lovegrove-Saville L, Mukuva P, Mustafa O. King's College Hospital NHS Foundation Trust (PRINCESS ROYAL UNIVERSITY HOSPITAL): Burwell S, Cheah Y, Mensah N, Mukuv P, O'Donell H, Lovie K, Whight E. Lancashire Teaching Hospitals NHS Foundation Trust (Chorley And South Ribble Hospital): Balmuri LMR, Imtiaz K. Leicester General Hospital (Leicester General Hospital): Dahya S, Gallagher A, Gohil S. London Medical, London (Private): Abraham R, Palik E, Willis C. London North West Healthcare NHS Trust (Brent Community Services): Anthony J, Carroll M, Godambe S, McCabe-Hughes F, Murali KS, Ogida L, Patel N, St-John J. Maidstone And Tunbridge Wells NHS Trust (The Tunbridge Wells $\mathrm{H}$ ospital): Agarwal G, Barnes D, Billings D, Butler C, Cairns S, Crosby Z, Danby T, Haq M, Ryan A. NHS Bury CCG (St Gabriel's Medical Centre): Deacon R. Oxford University Hospitals NHS Trust (Churchill Hospital): Lumb A, Scott K. Pennine Acute Hospitals NHS Trust: (Fairfield General Hospital): Tarpey S. Pennine Acute Hospitals NHS Trust (North Manchester General Hospital): Tarpey S. Pennine Acute Hospitals NHS Trust (Rochdale Infirmary): Tarpey S. Pennine Acute Hospitals NHS Trust (Royal Oldham Hospital): Tarpey S. Pleck Health Centre: Sinha S. Royal Free London NHS Foundation Trust (Barnet General Hospital): Cohen M, Katz J, Nogueira E. Royal Free London NHS Foundation Trust (Chase Farm Hospital): Baynes C. Royal United Hospital Bath NHS Trust: Robinson T. Sandwell And West Birmingham Hospitals NHS Trust (Cape Hill Medical Centre, GP): Gardner G. Sandwell And West Birmingham Hospitals NHS Trust (City Hospital Birmingham): Bajwa R, Basu A, Bingham E, Crabtree T, Cull ML, De P, Lee B, Kaur A, Kumar P, Pickles O, Potluri S, Ryder R E J, Sen Gupta P, Taylor N, Wyres M, Yadagiri M. Sandwell And West Birmingham Hospitals NHS Trust (Norvic Family Practice, GP): Baker O, Charm E, Littlewood Z. Pathan A, Wyres M. Sandwell And West Birmingham Hospitals NHS Trust (Dr P Pal \& Partner): Jemahl S, Wyres M. Sandwell And West Birmingham Hospitals NHS Trust (Park House Surgery, GP): Baker O, Hallan P, Turner M. Sandwell And West Birmingham Hospitals NHS Trust (Sherwood House Medical Practice, GP): Baker O, Hoffman H,
Turner M. Sandwell And West Birmingham Hospitals NHS Trust (Sundial Lane Surgery, Dr R Akhtar, GP): Akhtar R, Baker O, Durk D, Turner M, Woakes E, Wyres M. Sandwell And West Birmingham Hospitals NHS Trust (Tower Hill Medical Centre, Dr DK Nandis Practice, GP): Bath S, Chiam W. Sheffield Teaching Hospitals NHS Foundation Trust (Northern General Hospital): Hunt L Scott A. Selsdon Park Medical Practice (Selsdon Park Medical Practice): Burwell S, Cheah YS, Lovie K, Mensah N, Mukuva P, O'Donnell H, Whight E. Solent NHS Trust: Sharp P. South Warwickshire NHS Foundation Trust (Warwick Hospital): Pink G, Mahto R. Southern Health NHS Foundation Trust (Fenwick Hospital): Ayling C, Fayers K, Price H, McDonald M, Thorne K, Woodman S, Stockport NHS Foundation Trust (Buxton Cottage Hospital): Bell R. Stockport NHS Foundation Trust (Kingsgate House): Bell R. Stockport NHS Foundation Trust (Stockport NHS Foundation Trust): Bell R. Surrey and Sussex Healthcare NHS Trust (East Surrey Hospital): Brockett K, Clark J. The Royal Bournemouth And Christchurch Hospitals NHS Foundation Trust (Royal Bournemouth General Hospital): Hampton K, Partridge H, Walker J, Williams E. The Royal Wolverhampton NHS Trust (New Cross Hospital): Aziz U, Lekkakou L, Oguntolu V. United Lincolnshire Hospitals NHS Trust (Pilgrim Hospital): Azhar R, Jacob K. Western Sussex Hospitals NHS Trust (Worthing Hospital): Caldwell G, Iftikhar M. Whitstable Medical Practice (Dr Jm Ribchester \& Partners, GP): Brice R, Rollings R, Sansom H. Worcestershire Acute Hospitals NHS Trust (Alexandra Hospital): Tait K.

\section{Scotland}

Dr CP Macfarlane \& Partner: Smith L. Dr N S D Mackay \& Partner: Fabling M. Forestbank Medical Partne: Lyons S. Forth Valley Acute Hospitals NHS Trust: Barwell N, Buchanan L. Greater Glasgow \& Clyde: Huang F, Jones G. NHS Highland: McConnell L. NHS Fife (Victoria Hospital, Kirkcaldly): Adamson M, Baird J, Burns D, Chalmers J, Creagh M. Ochilview Practice: Oliver J. Royal Infirmary of Edinburgh NHS Trust: Adamson K, Reid H. West Lothian NHS Trust: Adamson K, Reid H, Vanlook L. Western General Hospitals NHS Trust: Adamson K, Reid H.

\section{Wales}

Abertawe Bro Morgannwg University NHS Trust (Morriston Hospital): Bain S C, Eyles J, Kumar P, Min T, Price D, Stephens JW. Abertawe Bro Morgannwg University NHS Trust (Neath Port Talbot Hospital): Chokor M, Peter R. Abertawe Bro Morgannwg University NHS Trust (Singleton Hospital): Bain S C, Eyles J. Abertawe Bro Morgannwg University NHS Trust (Swansea University): Bain S C, Eyles J. Betsi Cadwalader University Healthboard (Wrexham Maelor Hospital): Ahmad S, Khalily N, Stanaway S. Cardiff and Vale NHS Trust: Bolusani H, Eligar V, Roberts A. Hywel Dda NHS Trust: Kotonya C. LLANDUDNO GENERAL HOSPITAL SITE: Murtaza MO. YSBYTY GWYNEDD: Murtaza MO

\section{Northern Ireland}

Altnagelvin hospital, Londonderry Black N. Belfast Trust (Belfast City Hospital): Johnston PC, Lewis A, Nugent A, Todd A, McVeigh G, Wallace I. Northern Trust (Antrim Area Hospital): Kennedy A, Strzelecka A.

Northern Trust (Causeway Hospital): Abouzaid M, Gidwani S, Rooney D. Roe Valley Hospital: Black N. Royal Victoria Hospital, Belfast: Courtney $H_{\text {, }}$ Loughrey B. South West Acute Hospital: Black N. Tyrone County Hospital: Black N, Hameed A

\section{Hong Kong}

Hong Kong UMP: Chan W, Fung, Tsang Man Wo.

Brazil

Hospital Universitario Evangelico de Curitiba: Biagini GLK.

Australia

Rockingham General Hospital, Rockingham: Thong KY.

\section{Acknowledgment}

The $A B C D$ nationwide dapagliflozin audit is an independent audit supported by an unrestricted grant from AstraZeneca 